\title{
Anticoagulant Therapy for Disseminated Intravascular Coagulation After Gastrointestinal Surgery
}

\author{
DAISUKE HASHIMOTO ${ }^{1,2}$, TAKAOMI OKAWA ${ }^{2}$, RIICHIROH MARUYAMA ${ }^{3}$, \\ FUJIO MATSUMURA ${ }^{2}$, YUJI SHIBATA ${ }^{2}$ and HIROTSUGU KOHROGI ${ }^{4}$ \\ ${ }^{1}$ Department of Gastroenterological Surgery, Kumamoto University \\ Graduate School of Medical Sciences, Kumamoto, Japan; \\ ${ }^{2}$ Department of Gastroenterological Surgery, ${ }^{3}$ Department of Thoracic Surgery, and \\ ${ }^{4}$ Department of Respiratory Medicine, Omuta Tenryo Hospital, Omuta, Japan
}

\begin{abstract}
Many studies about anticoagulant therapy for disseminated intravascular coagulation (DIC) confused gastrointestinal surgery-related DIC with DIC unrelated to a prior operation. Furthermore, the potentially increased risk of bleeding by anticoagulants complicates their use. We carried out a systematic review to describe the efficacy and safety of anticoagulant agents for DIC after gastrointestinal surgery. Several studies have indicated that gabexate mesylate improves DIC score without increasing bleeding events, and that antithrombin is associated with lower mortality of DIC after gastrointestinal surgery. Recombinant thrombomodulin has been the most frequently analyzed anticoagulant agent in this field. DIC score and survival rate were better in patients treated with recombinant thrombomodulin, without increasing bleeding events. In conclusion, anticoagulant therapy may be effective and safe in DIC after gastrointestinal surgery.
\end{abstract}

Disseminated intravascular coagulation (DIC) frequently occurs in association with severe infections such as sepsis and malignancies $(1,2)$. Sepsis-induced DIC is a lifethreatening condition that involves systemic activation of blood coagulation that leads to the generation of intravascular fibrin, followed by multiple organ dysfunction syndrome, or even death $(3,4)$.

Correspondence to: Daisuke Hashimoto, MD, Ph.D., FACS, Department of Gastroenterological Surgery, Graduate School of Medical Sciences, Kumamoto University, 1-1-1 Honjo, Chuo-ku, Kumamoto, 860-8556 Japan. Tel: +81 963735212, Fax: +81 963714378,e-mail: daisukeh007@gmail.com

Key Words: Disseminated intravascular coagulation, operation, complication, bleeding, anticoagulant therapy, review.
Elective gastroenterological operations for malignancies usually lead to systemic inflammation and severe postoperative complications, such as intra-abdominal abscess formation, anastomotic leakage, pneumonia, and acute respiratory distress syndrome, and these conditions can be associated with DIC $(5,6)$. Moreover, emergency gastroenterological surgeries for an abdominal injury, perforation of ulceration, diverticulitis, or malignancies are associated with high morbidity and mortality rates, and postoperative sepsis and DIC often occur in such patients (7, $8)$. These operations are necessary to improve patients' conditions. However, such operations themselves are highly invasive. Therefore, the response of the patients to treatment for gastroenterological surgery-related DIC may differ from that for DIC unrelated to a prior surgery.

Recently, guidelines and consensus for the diagnosis and treatment of DIC were published in the United Kingdom (9), Japan (10), and Italy (11). These guidelines have mentioned various anticoagulant regents such as unfractionated heparin (UFH), low-molecular weight heparin (LMWH), danaparoid sodium (DS), gabexate mesylate (GM), nafamostat mesylate (NM), antithrombin (AT), and recombinant thrombomodulin (rhTM) (9-11). However, among the national guidelines, some differences in the recommendations for anticoagulant therapies exist. Additionally, many previous studies about the effects of various anticoagulant therapies on DIC confused DIC which was associated with gastroenterological surgery with DIC which was unrelated to an operation $(12,13)$. Furthermore, the potentially increased risk of bleeding as an adverse event of anticoagulant therapies has never been discussed in the treatment for DIC that has developed after gastroenterological surgery.

Thus, the optimal strategy for the management of DIC associated with gastroenterological surgery has been unclear to the surgical profession. To address this problem, we herein 
review the efficacy and safety of various anticoagulant therapies for DIC after gastrointestinal surgery.

\section{Materials and Methods}

Literature search strategy. This systematic review was conducted according to the Preferred Reporting Items for Systematic Reviews and Meta-Analyses guidelines, though a meta-analysis was not performed (14-16). The study protocol was approved by the institutional review board of Kumamoto University Hospital (\#1120). The National Library of Medicine [MEDLINE (PubMed, available at: http://www.pubmed.com/)] was systematically searched for studies reporting on anticoagulant therapies for DIC associated with gastrointestinal surgery. Only English-language publications published from 2000 to 2017 were selected. The selection process ensured that all articles included in the analysis were from peerreviewed journals.

Eligibility criteria and data collection. Studies on the prognosis of patients who were treated with anticoagulant agents for DIC after gastrointestinal surgery, were included. Clinical data such as platelet count, prothrombin time, DIC score, and associated adverse events such as postoperative bleeding, were considered especially important. Studies which confused surgery-related DIC with DIC unrelated to a prior operation were excluded. All study designs were considered, but reviews, editorials, letters to the editor, and opinion pieces were excluded. Additionally, case reports regarding a single case were excluded from this review. Titles and abstracts of retrieved references were screened for relevance by two independent reviewers (O. T. and M.R.). In case of disagreement, a third reviewer (M.F.) cast the deciding vote. In the same fashion, the full texts of the potential studies were further analyzed by two independent reviewers (S.Y. and K.H.) to see whether they met inclusion criteria. Disagreements at this stage were resolved by consensus and in consultation with a third reviewer (H. D.). The reviewers (O.T. and M.F.) extracted the data from the included articles. Figure 1 shows a flowchart of the descriptive analysis. Ultimately, seven articles were included in the analysis.

\section{Results}

$G M$. GM has a greater inhibitory effect on thrombin than on plasmin, and no fibrinolysis inhibition is observed at the ideal concentration for anticoagulation (17). GM has been applied to the treatment of DIC by some investigators and was confirmed to suppress thrombin-induced fibrinogenesis and fibrin deposition in organs and to inhibit platelet aggregation $(18,19)$. Only two studies focused on the efficacy of GM for DIC after gastrointestinal surgery $(20,21)$ (Table I).

In a retrospective study, Akahoshi et al. compared the effect of GM $(n=9)$ on DIC caused by sepsis after gastrointestinal surgery with that of rhTM $(n=10)(21)$. The most frequent cause of sepsis in both groups was colon perforation. The researchers indicated that there was no 28day mortality and no bleeding as an adverse effect in either group. However, acute DIC score improved significantly more in the rhTM group than in the GM group.
Hsu et al. conducted a randomized control trial (RCT) examining the effect of GM on DIC associated with infection after abdominal surgery (20). Twenty-five patients were randomized to receive treatment with GM, and the remaining 25 were not treated. Perforated peptic ulcer, acute cholangitis, and colon cancer were the most common etiologies in the GM group, compared with acute pancreatitis in the control group. The researchers indicated that DIC score was significantly lower in the GM group; however, there was no significant difference in the overall survival rate between the two groups (GM group, 76\% vs. control group, $67 \%$ ). Additionally, bleeding occurred in $8 \%$ of the GM group and $24 \%$ of the control group, but the difference was not statistically significant.

AT. AT is an endogenous coagulation inhibitor, but, as an adjunct therapy in sepsis-induced DIC, AT has been controversial $(22,23)$. Only two studies examined the effect of AT for DIC after emergency gastrointestinal surgery (24, 25) (Table II).

Itoh et al. analyzed the clinical course of 39 patients with peritonitis-induced DIC in their retrospective study, with results indicating the efficacy of rhTM (24). The most frequent cause of peritonitis was upper gastrointestinal tract perforation. In this study, 16 patients received AT. The researchers examined the effect of AT in a multivariate analysis, which showed no significant effect on overall survival. The incidence of bleeding events was unclear.

Tagami et al. performed a retrospective cohort study of patients with mechanically ventilated septic shock and DIC after emergency surgery for perforation of the lower intestinal tract using a nationwide administrative database, the Japanese Diagnosis Procedure Combination (DPC) inpatient database (25). There was no significant 28-day survival difference between the two unmatched groups (control $(\mathrm{n}=1,143) v s$. AT $(n=1,021)): 74.3 \%$ vs. $77.1 \%)$. Logistic regression analyses in a propensity-matched examination (521 patients in each group) showed a significant association between AT use and lower 28-day survival. However, this study has a serious limitation. The DPC database includes simple disease names and is used to make public health insurance judgments. Therefore, this study was not able to analyze DIC score, plasma AT level, and other clinical data, including bleeding events as an adverse effect.

rhTM. rhTM is a novel biological agent $(26,27)$. In addition to its effectiveness for DIC due to hematologic malignancy or infection, an anti-inflammatory mechanism of rhTM has also been reported $(12,13,26-28)$. rhTM has been the most frequently analyzed in this field. Five studies focused on the effect of rhTM on DIC after gastrointestinal surgery $(21,24$, 29-31) (Table III).

Akahoshi et al. retrospectively analyzed 19 DIC patients after emergency gastrointestinal surgery (21). As described 


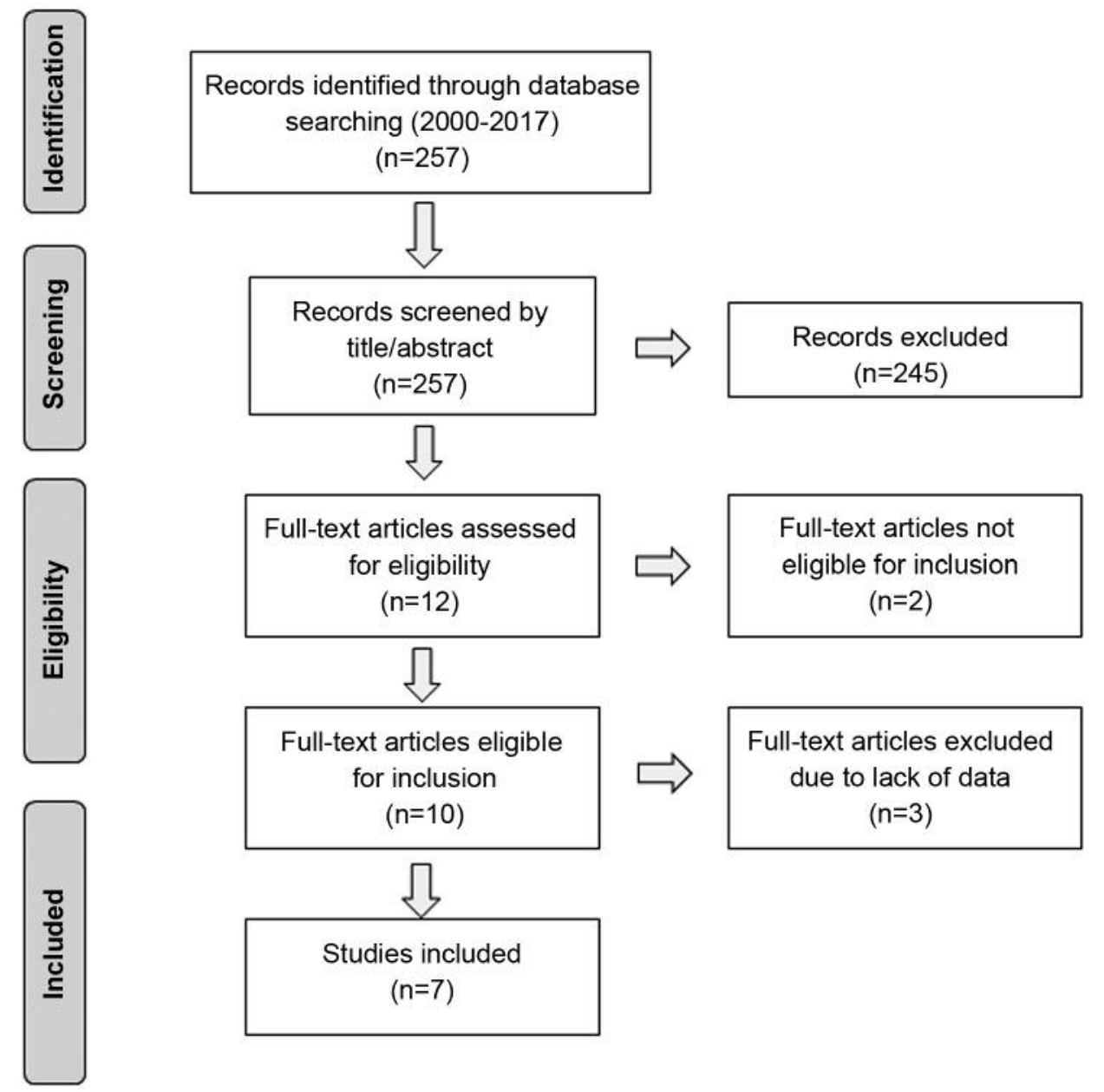

Figure 1. Flow-chart of the literature search process and extraction of studies meeting the inclusion criteria.

before, these patients received treatment with GM $(n=9)$ or rhTM $(n=10)$. There was no 28 -day mortality or postoperative bleeding in either group; however, acute DIC score in the rhTM group improved significantly earlier than in the GM group. In addition, C-reactive protein was recovered significantly earlier than in the GM group.

Hashimoto et al. performed a retrospective multicenter study including 156 patients with DIC associated with gastrointestinal surgery (29). Of these patients, 107 received rhTM and 49 did not. In both groups, the most frequent cause of DIC was perforation of the lower intestinal tract. Within seven days, the platelet count, prothrombin timeinternational normalized ratio, acute DIC score, neutrophil count, and C-reactive protein level significantly improved in the rhTM group compared with the control. Treatment with rhTM was significantly associated with better 28-day survival (rhTM group, $76.6 \%$ vs. control, 61.2\%). The incidence of adverse events did not differ between the two groups. Postoperative bleeding was observed in $0.9 \%$ of the rhTM group and $2.0 \%$ of the control group, and the incidence was not significantly different.

Itoh et al. indicated the effect of rhTM on peritonitisinduced DIC in their retrospective study (24). Thirty-four patients receiving rhTM had significantly better overall survival rates $(79.4 \%)$ at 28 days compared with those of 5 patients who did not receive rhTM $(40.0 \%)$, and the results of multivariate analysis showed that rhTM administration for DIC treatment was the only prognostic indicator of 28-day survival in patients with peritonitis. They did not show the incidence of adverse events such as bleeding.

Konishi et al. retrospectively investigated the efficacy of rhTM for treatment of 36 perioperative DIC patients after gastrointestinal surgery (30). Abscess formation and bacteremia were the most frequent causes of DIC. Although 
Table I. Efficacy and safety of gabexate mesylate on DIC after gastrointestinal surgery.

\begin{tabular}{lccccc}
\hline $\begin{array}{l}\text { Author/(ref)/ } \\
\text { year }\end{array}$ & $\begin{array}{c}\text { Study } \\
\text { design }\end{array}$ & $\begin{array}{c}\text { Procedure or etiology } \\
\text { of surgery before } \\
\text { DIC development }\end{array}$ & $\begin{array}{c}\text { Number of } \\
\text { patients }\end{array}$ & Survival & $\begin{array}{c}\text { Incidence of } \\
\text { bleeding event as } \\
\text { an adverse effect }\end{array}$ \\
\hline $\begin{array}{l}\text { Akahoshi (21) 2015 } \\
\text { Hsu (20) 2004 }\end{array}$ & $\begin{array}{c}\text { Retrospective } \\
\text { Randomized } \\
\text { control trial }\end{array}$ & $\begin{array}{l}\text { Gastrointestinal surgery } \\
\text { Gastrointestinal surgery }\end{array}$ & $\begin{array}{c}\text { GM 9 vs. rhTM 10 } 25 \text { vs. control 25 } \\
\text { G }\end{array}$ & $\begin{array}{c}100 \% \text { vs. 100\% (28-day) } \\
76 \% \text { vs. 67\% (overall) }\end{array}$ & $\begin{array}{c}0 \% \text { vs. 0\% } \\
8 \% \text {. 24\% } \\
\text { (gastrointestinal bleeding) }\end{array}$ \\
\hline
\end{tabular}

DIC: Disseminated intravascular coagulation; GM: gabexate mesylate; rhTM: recombinant thrombomodulin.

Table II. Efficacy and safety of antithrombin on DIC after gastrointestinal surgery.

\begin{tabular}{|c|c|c|c|c|c|}
\hline $\begin{array}{l}\text { Author/(ref)/ } \\
\text { year }\end{array}$ & $\begin{array}{l}\text { Study } \\
\text { design }\end{array}$ & $\begin{array}{l}\text { Procedure or etiology } \\
\text { of surgery before } \\
\text { DIC development }\end{array}$ & $\begin{array}{c}\text { Number of } \\
\text { patients }\end{array}$ & $\begin{array}{l}28 \text {-day } \\
\text { survival }\end{array}$ & $\begin{array}{c}\text { Incidence of } \\
\text { bleeding event as } \\
\text { an adverse effect }\end{array}$ \\
\hline Itoh (24) 2016 & Retrospective & $\begin{array}{c}\text { Peritonitis } \\
\text { (perforation or leakage) }\end{array}$ & $\begin{array}{l}\text { AT } 16 v s . \\
\text { control } 23\end{array}$ & $\begin{array}{l}\text { HR } 1.25, p=0.793 \\
\quad \text { (without AT) }\end{array}$ & Not Available \\
\hline Tagami (25) 2015 & $\begin{array}{c}\text { Retrospective, } \\
\text { using Japanese } \\
\text { DPC data }\end{array}$ & $\begin{array}{l}\text { Lower intestinal } \\
\text { perforation }\end{array}$ & $\begin{array}{l}\text { AT } 518 v s . \\
\text { control } 518\end{array}$ & $\begin{array}{c}80.1 \% \text { vs. } \\
72.4 \% *\end{array}$ & Not Available \\
\hline
\end{tabular}

AT: Antithrombin; DIC: disseminated intravascular coagulation; DPC: diagnosis procedure combination. *significant difference.

Table III. Efficacy and safety of recombinant thrombomodulin on DIC after gastrointestinal surgery.

\begin{tabular}{|c|c|c|c|c|c|}
\hline $\begin{array}{l}\text { Author/(ref)/ } \\
\text { year }\end{array}$ & $\begin{array}{l}\text { Study } \\
\text { design }\end{array}$ & $\begin{array}{l}\text { Procedure or etiology } \\
\text { of surgery before } \\
\text { DIC development }\end{array}$ & $\begin{array}{c}\text { Number of } \\
\text { patients }\end{array}$ & $\begin{array}{l}\text { 28-day } \\
\text { survival }\end{array}$ & $\begin{array}{c}\text { Incidence of } \\
\text { bleeding event as } \\
\text { an adverse effect }\end{array}$ \\
\hline Akahoshi (21) 2015 & Retrospective & Gastrointestinal surgery & rhTM 10 vs. GM 9 & $100 \%$ vs. $100 \%$ & $0 \%$ vs. $0 \%$ \\
\hline Hashimoto (29) 2015 & Retrospective & Gastrointestinal surgery & rhTM 107 vs. control 49 & $76.6 \%$ vs. $61.2 \% *$ & Minor $0.9 \%$ vs. $2.0 \%$ \\
\hline Itoh (24) 2016 & Retrospective & $\begin{array}{c}\text { Peritonitis } \\
\text { (perforation or leakage) }\end{array}$ & rhTM 34 vs. control 5 & $79.4 \%$ vs. $40 \% *$ & Not Available \\
\hline Konishi (30) 2017 & Retrospective & Gastrointestinal surgery & rhTM 36 & $71 \%$ & Major 0\%, Minor 19\% \\
\hline Tagami (31) 2015 & $\begin{array}{l}\text { Retrospective, } \\
\text { using Japanese } \\
\text { DPC data }\end{array}$ & $\begin{array}{l}\text { Lower intestinal } \\
\text { perforation }\end{array}$ & $\begin{array}{l}\text { rhTM } 621 \text { vs. } \\
\text { control } 621\end{array}$ & $73.9 \%$ vs. $75.2 \%$ & Not Available \\
\hline
\end{tabular}

DIC: Disseminated intravascular coagulation; DPC: diagnosis procedure combination; GM: gabexate mesylate; rhTM: recombinant thrombomodulin. *significant difference.

minor bleeding was observed in $19 \%$ of patients, DIC score, systemic inflammatory response syndrome score, and platelet count significantly improved after one week. The overall 28 day survival rate was $71 \%$. This study did not include patients who did not receive rhTM treatment as a control group.

Tagami et al. performed a retrospective cohort study of patients with mechanically ventilated septic shock and DIC after emergency surgery for perforation of the lower intestinal tract using the Japanese DPC database (31). There was neither significant difference in 28-day survival rate between the two groups in the unmatched analysis (rhTM $(\mathrm{n}=726) v s$. control $(\mathrm{n}=1,476), 74.7 \% v s .76 .6 \%)$ nor in the propensity-score-matched analysis (rhTM $(\mathrm{n}=621) v s$. control ( $\mathrm{n}=621), 73.9 \%$ vs. $75.2 \%$, respectively). However, this study has a serious limitation, similar to their study about AT using DPC data (25). This study did not analyze platelet count, prothrombin time, DIC score, and other clinical data, including bleeding events. 
Other anticoagulant agents. Several retrospective analyses reported that concomitant UFH improved 28-day survival of severe septic patients $(23,32,33)$. A multicenter prospective RCT indicated that LMWH has significantly higher safety and clinical utility compared with heparin in the treatment of DIC (34). However, no studies have focused on the effect of these anticoagulant agents, including UFH, LMWH, DS, or NM, on DIC associated with gastrointestinal surgery.

\section{Discussion}

Despite recent advances in surgical techniques, interventional radiology, and perioperative intensive care support, morbidity rates after gastrointestinal surgery remain high (35-38). In addition, in-hospital mortality of gastrointestinal surgery remains at $2-3 \%$ in nationwide studies, because of complications such as anastomotic leakage and abdominal abscess (35-38). Both of these severe postoperative complications after elective and emergency gastrointestinal surgery are highly associated with sepsis followed by DIC (7, 8, 39, 40). Thus, treatment strategies for DIC and guidelines for the use of anticoagulant agents are important for gastrointestinal surgeons.

Postoperative bleeding is a major complication after gastrointestinal surgery $(36-38,41-43)$. Therefore, the potentially increased risk of bleeding is the greatest concern when anticoagulant agents are administered to postoperative patients.

In this study, we reviewed seven studies that focused on these problems. One RCT indicated that GM reduced DIC score, but, did not reduce mortality (20). In that study, the etiology of surgery was not well balanced between the groups, and the incidence of postoperative bleeding was unclear. Two retrospective studies analyzed the effect of AT on DIC after gastrointestinal surgery $(24,25)$. One of those indicated that treatment with AT was associated with better prognosis in propensity score-matched analysis; however, this study was not able to evaluate clinical data, including DIC score, plasma AT level, and bleeding events (25). rhTM has been the most frequently analyzed anticoagulant agent in DIC after gastrointestinal surgery $(21,24,29-31)$. Acute DIC score was improved by rhTM in three studies $(21,29,30)$. The 28 -day survival rate of the rhTM group was better than the control group in two studies $(24,29)$. Additionally, the incidence of bleeding events as an adverse effect was not increased (21, 29, 30). No studies of DIC after gastrointestinal surgery have focused on the effect of UFH, LMWH, DS, or NM. Indeed, guidelines and consensus have not strongly recommended these drugs for the treatment of DIC, whatever the etiology (9-11). These results are generally consistent with a recent nationwide multicenter retrospective observational study of sepsis-induced DIC in Japan (44).
Guidelines and consensus for DIC suggested that DIC should be categorized into several types and treated in accordance with the type of DIC (9-11). However, they did not distinguish DIC which was associated with surgery with DIC which was unrelated to an operation. DIC after gastrointestinal surgery is probably categorized as organ disorder type DIC (10). For this type, AT and rhTM are recommended (recommended degree $\mathrm{B}_{1}$ ) rather than other anticoagulants (10). Although the results of this review are consistent with this recommendation, guidelines should mention surgery-related DIC for better understanding and clinical practice for surgeons

Some related research tasks should be attended to in the future. First, there have been few RCTs or prospective studies able to evaluate the effect of anticoagulant therapy on DIC after gastrointestinal surgery. It is possible that anticoagulant therapy has not been introduced for patients with high risk of bleeding, owing to clinical decisions by the attending surgeons. Second, the etiologies and procedures of surgeries performed before development of DIC were inconsistent across studies, although perforation of lower digestive tract was the most common etiology.

In conclusion, anticoagulant therapy may be effective in DIC associated with gastrointestinal surgery without increasing the risk of bleeding as an adverse event. However, the use of anticoagulants remains controversial in a strict sense, and further studies including more patients should be planned to solve the problem.

\section{Acknowledgements}

The Authors would like to thank Edanz Group (www.edanzediting. com/ac) for English proofreading a draft of this manuscript.

\section{Conflicts of Interest}

The Authors report no proprietary or commercial interest in any product mentioned or concept discussed in this article.

\section{References}

1 Levi $\mathrm{M}$ and Ten Cate H: Disseminated intravascular coagulation. N Engl J Med 341: 586-592, 1999.

2 Toh $\mathrm{CH}$ and Dennis M: Disseminated intravascular coagulation: old disease, new hope. BMJ 327: 974-977, 2003.

3 Levi $\mathrm{M}$ and van der Poll T: Inflammation and coagulation. Crit Care Med 38: S26-S34, 2010.

4 Esmon CT: The interactions between inflammation and coagulation. Br J Haematol 131: 417-430, 2005.

5 Holzheimer RG and Gathof B: Re-operation for complicated secondary peritonitis - how to identify patients at risk for persistent sepsis. Eur J Med Res 8: 125-134, 2003.

6 Kiewiet JJ, van Ruler O, Boermeester MA and Reitsma JB: A decision rule to aid selection of patients with abdominal sepsis requiring a relaparotomy. BMC Surg 13: 28, 2013. 
7 Tridente A, Clarke GM, Walden A, McKechnie S, Hutton P, Mills GH, Gordon AC, Holloway PA, Chiche JD, Bion J, Stuber F, Garrard C and Hinds CJ: Patients with faecal peritonitis admitted to European intensive care units: an epidemiological survey of the GenOSept cohort. Intensive Care Med 40: 202-210, 2014.

8 Kim SY, Oh TH, Seo JY, Jeon TJ, Seo DD, Shin WC, Choi WC and Jeong MJ: The clinical factors for predicting severe diverticulitis in Korea: a comparison with Western countries. Gut Liver 6: 78-85, 2012.

9 Levi M, Toh CH, Thachil J and Watson HG: Guidelines for the diagnosis and management of disseminated intravascular coagulation. British Committee for Standards in Haematology. Br J Haematol 145: 24-33, 2009.

10 Wada H, Asakura H, Okamoto K, Iba T, Uchiyama T, Kawasugi K, Koga S, Mayumi T, Koike K, Gando S, Kushimoto S, Seki Y, Madoiwa S, Maruyama I and Yoshioka A: Expert consensus for the treatment of disseminated intravascular coagulation in Japan. Thromb Res 125: 6-11, 2010.

11 Di Nisio M, Baudo F, Cosmi B, D'Angelo A, De Gasperi A, Malato A, Schiavoni $M$ and Squizzato A: Diagnosis and treatment of disseminated intravascular coagulation: guidelines of the Italian Society for Haemostasis and Thrombosis (SISET). Thromb Res 129: e177-e184, 2012.

12 Mimuro J, Takahashi H, Kitajima I, Tsuji H, Eguchi Y, Matsushita $\mathrm{T}$, Kuroda $\mathrm{T}$ and Sakata Y: Impact of recombinant soluble thrombomodulin (thrombomodulin alfa) on disseminated intravascular coagulation. Thromb Res Suppl 131: 436-443, 2013.

13 Saito H, Maruyama I, Shimazaki S, Yamamoto Y, Aikawa N, Ohno R, Hirayama A, Matsuda T, Asakura H, Nakashima M and Aoki N: Efficacy and safety of recombinant human soluble thrombomodulin (ART-123) in disseminated intravascular coagulation: results of a phase III, randomized, double-blind clinical trial. J Thromb Haemost 5: 31-41, 2007.

14 Liberati A, Altman D, Tetzlaff J, Mulrow C, Gøtzsche P, Ioannidis J, Clarke M, Devereaux P, Kleijnen J and Moher D: The PRISMA statement for reporting systematic reviews and meta-analyses of studies that evaluate health care interventions: explanation and elaboration. Ann Intern Med 151: w65-w94, 2009.

15 Moher D, Shamseer L, Clarke M, Ghersi D, Liberati A, Petticrew M, Shekelle P, Stewart L and PRISMA-P G: Preferred reporting items for systematic review and meta-analysis protocols (PRISMA-P) 2015 statement. Syst Rev 1: 1, 2015.

16 Shamseer L, Moher D, Clarke M, Ghersi D, Liberati A, Petticrew M, Shekelle P, Stewart L and PRISMA-P G: Preferred reporting items for systematic review and meta-analysis protocols (PRISMA-P) 2015: elaboration and explanation. BMJ 2: g7647, 2015.

17 Ohno H, Kambayashi J, Chang S and Kosaki G: FOY: [ethyl p(6-guanidinohexanoyloxy) benzoate] methanesulfonate as a serine proteinase inhibitor. II. In vivo effect on coagulofibrinolytic system in comparison with heparin or aprotinin. Thromb Res 24: 445-452, 1981.

18 Tamaki S, Wada H, Hiyoyama K, Shimura M, Minamikawa K, Wakita Y, Nakase T, Ohiwa M, Kaneko T and Iwasaki E: Treatment of disseminated intravascular coagulation with gabexate mesilate. Clin Ther 15: 1076-1084, 1993.

19 Yokota T, Yamada Y, Takahashi M, Kunii Y, Iwamoto K, Kagami M, Kikuchi S, Yamauchi $\mathrm{H}$ and Yoshikawa K: Successful treatment of DIC with a serine proteinase inhibitor. Am J Emerg Med 19: 334-335, 2001.
20 Hsu J, Chen H, Chiu D, Chen J, Huang C, Hwang T, Jan Y and Chen M: Efficacy of gabexate mesilate on disseminated intravascular coagulation as a complication of infection developing after abdominal surgery. J Formos Med Assoc 103: 678-684, 2004.

21 Akahoshi T, Sugimori H, Kaku N, Tokuda K, Nagata T, Noda E, Morita M, Hashizume $\mathrm{M}$ and Maehara $\mathrm{Y}$ : Comparison of recombinant human thrombomodulin and gabexate mesylate for treatment of disseminated intravascular coagulation (DIC) with sepsis following emergent gastrointestinal surgery: a retrospective study. Eur J Trauma Emerg Surg 41: 531-538, 2015.

22 Fourrier F, Chopin C, Huart J, Runge I, Caron C and Goudemand J: Double-blind, placebo-controlled trial of antithrombin III concentrates in septic shock with disseminated intravascular coagulation. Chest 104: 882-888, 1993.

23 Warren B, Eid A, Singer P, Pillay S, Carl P, Novak I, Chalupa P, Atherstone A, Pénzes I, Kübler A, Knaub S, Keinecke H, Heinrichs H, Schindel F, Juers M, Bone R and Opal S: Caring for the critically ill patient. High-dose antithrombin III in severe sepsis: a randomized controlled trial. JAMA 286: 1869-1878, 2001.

24 Itoh S, Shirabe K, Kohnoe S, Sadanaga N, Kajiyama K, Yamagata M, Anai H, Harimoto N, Ikegami T, Yoshizumi T and Maehara Y: Impact of recombinant human soluble thrombomodulin for disseminated intravascular coagulation. Anticancer Res 36: 24932496, 2016

25 Tagami T, Matsui H, Fushimi K and Yasunaga H: Supplemental dose of antithrombin use in disseminated intravascular coagulation patients after abdominal sepsis. Thromb Haemost 114: 537-545, 2015.

26 Abeyama K, Stern DM, Ito Y, Kawahara K, Yoshimoto Y, Tanaka M, Uchimura T, Ida N, Yamazaki Y, Yamada S, Yamamoto Y, Yamamoto $\mathrm{H}$, Ino $\mathrm{S}$, Taniguchi $\mathrm{N}$ and Maruyama I: The $\mathrm{N}-$ terminal domain of thrombomodulin sequesters high-mobility group-B1 protein, a novel antiinflammatory mechanism. J Clin Invest 115: 1267-1274, 2005.

27 Ito T, Kawahara K, Okamoto K, Yamada S, Yasuda M, Imaizumi H, Nawa Y, Meng X, Shrestha B, Hashiguchi T and Maruyama I: Proteolytic cleavage of high mobility group box 1 protein by thrombin-thrombomodulin complexes. Arterioscler Thromb Vasc Biol 28: 1825-1830, 2008.

28 Aikawa N, Shimazaki S, Yamamoto Y, Saito H, Maruyama I, Ohno R, Hirayama A, Aoki Y and Aoki N: Thrombomodulin alfa in the treatment of infectious patients complicated by disseminated intravascular coagulation: subanalysis from the phase 3 trial. Shock 35: 349-354, 2011.

29 Hashimoto D, Chikamoto A, Miyanari N, Ohara C, Kuramoto M, Horino K, Ohshima $\mathrm{H}$ and Baba H: Recombinant soluble thrombomodulin for postoperative disseminated intravascular coagulation. J Surg Res 197: 405-411, 2015.

30 Konishi H, Okamoto K, Shoda K, Arita T, Kosuga T, Morimura R, Komatsu S, Murayama Y, Shiozaki A, Kuriu Y, Ikoma H, Nakanishi M, Ichikawa D, Fujiwara H and Otsuji E: Early thrombomodulin-a administration outcome for acute disseminated intravascular coagulopathy in gastrointestinal surgery. World J Gastroenterol 23: 891-898, 2017.

31 Tagami T, Matsui $\mathrm{H}$, Fushimi $\mathrm{K}$ and Yasunaga $\mathrm{H}$ : Use of recombinant human soluble thrombomodulin in patients with sepsis-induced disseminated intravascular coagulation after intestinal perforation. Front Med (Lausanne) 2: 7, 2015. 
32 Bernard G, Vincent J, Laterre P, LaRosa S, Dhainaut J, LopezRodriguez A, Steingrub J, Garber G, Helterbrand J, Ely E and Fisher CJ: Efficacy and safety of recombinant human activated protein C for severe sepsis. N Engl J Med 344: 699-709, 2001.

33 Abraham E, Reinhart K, Opal S, Demeyer I, Doig C, Rodriguez A, Beale R, Svoboda P, Laterre P, Simon S, Light B, Spapen H, Stone J, Seibert A, Peckelsen C, De Deyne C, Postier R, Pettilä V, Sprung C, Artigas A, Percell S, Shu V, Zwingelstein C, Tobias J, Poole L, Stolzenbach J and Creasey A: Efficacy and safety of tifacogin (recombinant tissue factor pathway inhibitor) in severe sepsis: a randomized controlled trial. JAMA 290: 238-247, 2003.

34 Sakuragawa N, Hasegawa H, Maki M, Nakagawa $M$ and Nakashima M: Clinical evaluation of low-molecular-weight heparin (FR-860) on disseminated intravascular coagulation (DIC) - a multicenter co-operative double-blind trial in comparison with heparin. Thromb Res 72: 475-500, 1993.

35 Miyata H, Gotoh M, Hirai I, Kenjo A, Kitagawa Y, Shimada M, Baba H, Tomita N, Nakagoe T, Sugihara K and Mori M: A pancreaticoduodenectomy risk model derived from 8575 cases from a national single-race population (Japanese) using a webbased data entry system: the 30-day and in-hospital mortality rates for pancreaticoduodenectomy. Ann Surg 259: 773-780, 2014.

36 Watanabe M, Miyata H, Gotoh M, Baba H, Kimura W, Tomita N, Nakagoe T, Shimada M, Kitagawa Y, Sugihara K and Mori M: Total gastrectomy risk model: data from 20,011 Japanese patients in a nationwide internet-based database. Ann Surg 260: 1034-1039, 2014.

37 Kobayashi H, Miyata H, Gotoh M, Baba H, Kimura W, Kitagawa Y, Nakagoe T, Shimada M, Tomita N, Sugihara K and Mori M: Risk model for right hemicolectomy based on 19,070 Japanese patients in the National Clinical Database. J Gastroenterol 49: 1047-1055, 2014.

38 Anazawa T, Paruch J, Miyata H, Gotoh M, Ko C, Cohen M, Hirahara N, Zhou L, Konno H, Wakabayashi G, Sugihara K and Mori M: Comparison of national operative mortality in gastroenterological surgery using web-based prospective data entry systems. Medicine 94: e2149, 2015.
39 Yamakawa K, Aihara M, Ogura H, Yuhara H, Hamasaki T and Shimazu T: Recombinant human soluble thrombomodulin in severe sepsis: a systematic review and meta-analysis. J Thromb Haemost 13: 508-519, 2015.

40 Hashimoto D, Hirota M, Matsukawa T, Yagi Y and Baba H: Clinical features of strangulated small bowel obstruction. Surg Today 42: 1061-1065, 2012.

41 Kenjo A, Miyata H, Gotoh M, Kitagawa Y, Shimada M, Baba H, Tomita N, Kimura W, Sugihara K and Mori M: Risk stratification of 7,732 hepatectomy cases in 2011 from the national clinical database for Japan. J Am Coll Surg 218: 412422, 2014.

42 Yamashita Y, Taketomi A, Fukuzawa K, Tsujita E, Harimoto N, Kitagawa D, Kuroda Y, Kayashima H, Wakasugi K and Maehara Y: Risk factors for and management of delayed intraperitoneal hemorrhage after pancreatic and biliary surgery. Am J Surg 193: 454-459, 2007.

43 Koami H, Sakamoto Y, Sakurai R, Ohta M, Imahase H, Yahata M, Umeka M, Miike T, Nagashima F, Iwamura T, Yamada K and Inoue $\mathrm{S}$ : The efficacy and associated bleeding complications of recombinant antithrombin supplementation among intensive care unit patients. Thromb Res 157: 84-89, 2017.

44 Hayakawa M and Ono K: A summary of the Japan septic disseminated intravascular coagulation study. Acute Med Surg 5: 123-128, 2018.
Received November 29, 2018

Revised December 7, 2018

Accepted December 10, 2018 